\title{
The Effect of Student's Gender and presence on Academic Performance in Amhara Region with special reference to University of Gondar, Ethiopia
}

\author{
* Mr.Wondim Awoke Kassa, **Dr.Kavitha Nachimuthu,
}

Lecturer, Department of Rural Development and Agricultural Extension, College of Agriculture and Rural Transformation, University of Gondar, Ethiopia.

Associate Professor, Department of Rural Development and Agricultural Extension, College of Agriculture and Rural Transformation, University of Gondar, Ethiopia.

\begin{abstract}
Quality education is the crucial for over development of the country. But there are different challenges for student to get quality education which led for poor academic performance. The study was conducted in the University of Gondar, Ethiopia to examine determinants of academic performance of the student. It was conducted at the second semester results of the final score in three courses for the academic year 2016/17 (Farming System Research and Innovation, Innovation System and Agricultural and Rural Extension). The courses were delivered for second year rural development and agricultural extension, adult education and community development $2^{\text {nd }}$ year and animal production and extension $3^{\text {rd }}$ year in the University of Gondar. Totally 118 students considered and stratified as male and female to compare and contrast the academic performance based on their attendance and total score. The multiple regressions was used to carried out to determine the impact of students' attendance and gender (being male and female) at teaching and learning process in their final academic performance. The study reveals that female students attained more than male student but on average they perform less than male students. Both gender and attendance have significant effect on academic performance of the student. Gender was significant at $1 \%$ probability and attendance was significant at $1 \%$. Therefore, university should give emphasis for these determinants and further study should be conducted to identify other factors which hinder academic performance of the student.
\end{abstract}

Keywords: Academic performance, Attendance, Gender, Students and Ethiopia

\section{Background and justification}

The education of today is crucial to enhancing the ability of the people to create solutions and find new paths for more sustainable future development. Hence, the needs of the people should be considered and addressed through quality education (UNESCO, 2012). However, country's education systems are entangled with complex problems of relevance, quality, accessibility, equity and enrich problem-solving ability and attitude. So, government of Ethiopia emphasized that higher institution should integrated education with research, practice and development to contribute towards an all rounded development of society (FDRE, 1994).

Considering the national policy of the country the University of Gondar stands for dissemination of advanced scientific knowledge through performing activities of teaching, research and community service 
for enhancing the nation's development. Student-centered education is one of the university strategies which support the achievement of the major national goals (Senate Legislation of university, 2013). So that to attain such vision as well as the attainment of its mission and values identifying factors that affect students' academic performance have paramount role.

Different scholars tried to identify factors that affect academic performance of the student in world or national level which is an obstacle for the quality education. According to the Farooq and etal.., 2011 factors that affect academic performance of the student were socio economic status, school, peer and student factors, parental occupation and student's gender. In addition to these attendance and gender has a big influence in students' academic performance. Attendance has main reason for the student's academic performance (Shaikha Hassan Jameel and Allam Hamdan, 2015; Nigel Halpern, 2017; Syed Tahir Hijazi; S.M.M. Raza Naqvi, 2006; Pudaruth and etal, 2013; Sadri ALIJA, 2013). But according to the Rizwan Faisal and etal. (2017) there was no effect of attendance on academic performance of the student i.e. insignificant. Besides to the above mentioned determinant gender was also another determining factor for academic performance of the student (Mohannad Eid AbuRuz, 2015, Meltem Dayıglu and Serap TürütAs1k, 2004; Muhammad Riaz Ahmad and etal., 2015).

Determining all the influencing factors in a short period of time is a complex and difficult task. Because, it requires a lot of time, human and financial resources. There is little/no empirical evidence on determinants of academic performance of student in Ethiopia particularly University of Gondar. Studies conducted were not comprised gender and attendance as determinant of academic performance. Therefore, it was in this background that comparing and examining the effect of student's gender and attendance on their academic performance was conducted to fill the information gap with regard to academic performance in the University of Gondar.

\section{Objective}

a To compare and contrast the academic performance of male and female students based on their attendance.

a To examine the effect of student's gender and attendance on their academic performance.

\section{Methodology}

Sampling Techniques and Sample Size

The research considered the whole students (population) for study on the effect of student's gender and attendance on academic performance. The students were stratified as male and female to compare and contrast the academic performance of male and female students based on their attendance and total score. The number of students considered for the study in each department was AECD 32 (male 13 and female 19), 
RDAE 40 (male 23, female 17) and APEX 46 (male 27 and female 19). Therefore, the total numbers of the students who are considered for the study were 118 from the three departments.

\section{Data Collection}

Both quantitative and qualitative data were collected from secondary and primary data sources through appropriate data collection tools. The secondary data about the name and gender was taken from each department before the beginning of the class. The data regarding to the final result was collected among three different departments by the same instructor. For each department one quiz, two test and one assignment from total 50\% was taken and final from 50\% was given. Totally out of $100 \%$ result for each course were recorded and summarized systemically during the academic year 2016/2017. Mechanisms used to avoid cheating during continuous assessment (50\%) were providing different topic of the assignment having same method for writing up, making sitting arrangement and coding each test. From the final exam university has its own way of controlling mechanism of cheating. Attendance at each teaching session was recorded for each course through the use of prepared attendance sheet with sign in sheet. The attendance was circulated and taken at end of each session. At the end of the session, the sheet with the students' signature was cross checked through calling their name in order to avoid cheating. The information from the sheets was then recorded electronically in a Microsoft Excel.

\section{Data Analysis}

To attain the stated objective the data collected were analyzed through descriptive and econometrics analysis. In the descriptive part of the analysis minimum, maximum, mean and percentage was used. Where multiple regression model was used for the econometrics analysis part of data. Statistical Package for Social Sciences (SPSS) version 20 was utilized to carry out analysis.

\section{Econometric analysis}

Multiple regression analysis was utilized to carry out effect of gender and attendance as independent variables on student's performance as dependent variable. Therefore, the mathematical specification of the model is

$\mathrm{Y}=\beta \mathrm{o}+\beta 1 \mathrm{X} 1+\beta 2 \mathrm{X} 2+\beta 3 \mathrm{X} 3 \ldots \ldots \ldots+\beta \mathrm{Xn}$

Where, $\mathrm{Y}=$ dependent variable

$\beta \mathrm{O}=$ the slope of the equation

$\beta 1 \ldots \beta 2 \ldots \beta n=$ coefficients to estimates

$\mathrm{X} 1 \ldots \mathrm{X} 2 \ldots \ldots . \mathrm{Xn}=$ independent variables

Variable Definition and Hypothesis for the Student's Academic Performance 
The main task of checking whether gender and attendance influence the academic performance of student was to exploring which factors potentially influence and how (the direction of the relationship) these factors are related with the dependent variable.

\section{Dependent Variable:}

Student's academic performance: It is a continuous variable representing dependant variable. It is total score of students result attained at the end of semester and measured in number.

\section{The Independent Variables:}

Gender: Gender is measured as a dummy variable taking value of 1 if the student is male and 2 if the student is female. Being male or female has no any effect on decreasing the academic performance of the student. It is assumed to have positive contribution to academic performance of the student.

Attendance: is a continuous variable and number of day a student attending the class. A student with better habit in attending the class is expected to perform better than one with only less habit to attend the class. Therefore, attending the class has expected to have positive relation with academic performance of the student.

\section{Result and discussion}

From the total number of the students 55 (46.6\%) were female where 63 (53.4\%) were male students. As shown in table 1 below the result of descriptive statistics indicate that there is a difference in the attendance of the male and female students. Female students were better attendant of class but there is a little bit difference in mean result compared to the male students i.e female students attain less than male students.

From three courses male students attended $78.56 \%$ minimum from innovation system course where as female students attend $85.67 \%$ maximum from the course farming system research and innovation. Students were attended these courses on the mean averages $83.43 \%$.

The finding of the Mohannad Eid AbuRuz, 2015, indicates that male students have higher absenteeism rates and lower GPAs than females. But based on descriptive statistic result finding of these research revealed that on average male students have higher absenteeism rates and higher result/ score than females. According to Shaikha Hassan Jameel and Allam Hamdan (2015) regular attendance from childhood at school is crucial for the better performance. So that missing lower grade but attending higher level may be difficult to better performance.

Table 1. Comparison of Male and Female Students based on Course Attendances

\begin{tabular}{|l|l|l|l|l|}
\hline Courses & Gender & $\mathrm{N}$ & Attendance in (\%) & Absence in (\%) \\
\hline $\begin{array}{l}\text { Farming system Research and } \\
\text { innovation }\end{array}$ & Male & 23 & 85.56 & 14.44 \\
\cline { 2 - 6 } & Female & 17 & 85.67 & 14.33 \\
\hline Agricultural and rural extension & Male & 13 & 84.67 & 15.33 \\
\hline
\end{tabular}




\begin{tabular}{|l|l|l|l|l|}
\hline & Female & 19 & 83.67 & 16.33 \\
\hline Innovation system & Male & 27 & 78.56 & 21.44 \\
\cline { 2 - 5 } & Female & 19 & 82.44 & 17.56 \\
\hline
\end{tabular}

\section{Academic Performances Of University Of Gondar Students}

The results of descriptive statistics indicate that there is a difference in the total score of the male and female students. Without disintegration of gender the minimum, maximum and mean result out of 100\% was 33.69, 96.00 and 64.88, respectively Female students score minimum and maximum from the course agricultural and rural extension (42\%) and (96\%), respectively. Male students score minimum from the course innovation system (33.69\%) and score maximum from agricultural and rural extension course (90\%). The minimum result was scored by male and maximum result was scored by female student (Apendix1). However, on average male students perform better than the female having mean value of male 67.09 and female 62.34. Different scholars result indicates that female students perform better than the male (Chambers \& Schreiber, 2004; Farooq and etal.., 2011; Meltem Dayıglu and Serap Türüt-As1k, 2004; Muhammad Riaz Ahmad and etal., 2015).

Table 2: Comparison of Male and Female Students based on Academic performance

\begin{tabular}{|l|l|l|l|}
\hline Courses & Gender & $\mathrm{N}$ & Score in (\%) \\
\hline Farming system Research and innovation & Male & 23 & 69.23 \\
\cline { 2 - 4 } & Female & 17 & 55.28 \\
\hline Agricultural and rural extension & Male & 13 & 73.96 \\
\cline { 2 - 4 } & Female & 19 & 67.87 \\
\hline Innovation system & Male & 27 & 61.97 \\
\cline { 2 - 4 } & Female & 19 & 63.14 \\
\hline
\end{tabular}

\section{Econometric Model Outputs}

\section{Determinants of student academic performance (gender and attendance)}

According to the research even if there was variation in result/ student performance to attain good result, the entire student put their effort to attain good result. Therefore, analyzing gender and attendance as determinants performance of student by using multiple linear regressions was important. Before running the model, all the hypothesized explanatory variables were checked whether multiple regression assumptions were violated or not. The key assumptions of multiple regressions such as linear relationship, homoscedasticity, independent errors, outliers /influential cases, variance in all predictors, multi co linearity and normally distributed residuals were checked through appropriate test for each assumption. For instance, multi-co linearity through VIF (it should be less than 10) if so multi-co linearity was not a serious problem among the variables. 
The result of the study indicates that the VIF value for both variables was 1.016. The result indicates that multi-co linearity was not a serious problem among the variables since VIF results were less than 10 (Table $5)$.

Table: 3 The econometric model

\begin{tabular}{|c|r|r|r|}
\hline R & R Square & Adjusted R Square & Std. Error of the Estimate \\
\hline .64 & .41 & .40 & 10.47 \\
\hline
\end{tabular}

The econometric model result shows that the coefficient of determination $\left(\mathrm{R}^{2}\right)$ value was 0.41 . Based on this value $41 \%$ of the variation in result/score can be attributed to attendance and gender. But $59 \%$ academic performance of the student is explained by other determinants. Both explanatory variables were determining significantly the student's academic performance.

Table:4 Descriptive Statistics of Academic performance

\begin{tabular}{|l|l|l|l|l|l|l|l|}
\hline & \multicolumn{2}{|l|}{$\begin{array}{l}\text { Score from farming } \\
\text { system Research and } \\
\text { innovation }\end{array}$} & \multicolumn{2}{l|}{$\begin{array}{l}\text { Score from } \\
\text { agricultural and } \\
\text { rural extension }\end{array}$} & $\begin{array}{l}\text { Score innovation } \\
\text { system }\end{array}$ & $\begin{array}{l}\text { Overall } \\
\text { courses } \\
\text { score }\end{array}$ \\
\hline Gender & $\mathrm{M}$ & $\mathrm{F}$ & $\mathrm{M}$ & $\mathrm{F}$ & $\mathrm{M}$ & $\mathrm{F}$ & \\
\hline Minimum & 39.00 & 42.50 & 59.25 & 42.00 & 33.69 & 45.80 & 33.69 \\
\hline Maximum & 88.75 & 73.50 & 90.00 & 96.00 & 87.05 & 88.00 & 96.00 \\
\hline Std. Deviation & 11.34 & 8.87 & 9.64 & 18.15 & 13.96 & 9.86 & 13.55 \\
\hline
\end{tabular}

Attendance: As hypothesized the attendance was positive and significantly at $1 \%$ probability level, a positive coefficient implies that an attending the class would increase the academic performance of the student. It shows that a student who has attending the class has better information would have better know how about the course and achieve better result. Means a student that attained class are likely to perform more than student who did not attained class. The result of study indicated that an increase a unit in attending the course leads will increase his/her academic performance by 4.48 units. The result indicates that the relationship between course attendances and academic performance is statistically significant and has positive relationship. This is in line with the result of (Ahmed Abdi Aden, 2013; Mohannad Eid AbuRuz, 2015, Vincenzo Andrietti_Rosaria D’Addazio, 2012; Paul LeBlnc III, 2005; Shaikha Hassan Jameel and Allam Hamdan, 2015; Nigel Halpern, 2017; Syed Tahir Hijazi and S.M.M. Raza Naqvi, 2006). However, the result indicates that Kyoshaba Martha (2009) there was no significance difference between attendance and academic performance. 
Gender: The result has showed significant effect at $1 \%$ significant level for academic performance of the student contrary to hypothesis. As result academic performance of the student may be decreased. The result implied that as student's gender being male or female increase by one unit, the academic performance of student reduces by 5.48 units' i.e. they have inverse relation. According to the R.Bada.Abubakar and O.Dokubo Oguguo (2011) gender is significant and positive interaction on student's academic achievement. But some scholars obtained that gender has no significant difference between the academic performance of students (Rizwan Faisal and etal., 2017; Peter Ogbianigene Dania,2014; E.E. Ebenuwa-Okoh, 2010).

Table 5: Determinants of student performance (gender and attendance)

\begin{tabular}{|l|r|r|r|r|r|r|}
\hline Variables & \multicolumn{2}{|l|}{ Coefficients } & \multirow{2}{*}{ T } & \multicolumn{2}{l|}{ Sig. } & \multicolumn{2}{l|}{ Collinearity Statistics } \\
\cline { 2 - 3 } & \multicolumn{1}{|c|}{ B } & Std. Error & & & Tolerance & VIF \\
\hline (Constant) & 31.59 & 5.53 & 5.72 & .000 & & \\
\hline Attendance & 5.53 & .64 & 8.66 & .000 & .998 & 1.002 \\
\hline Gender & -5.48 & 1.93 & -2.84 & .005 & .998 & 1.002 \\
\hline
\end{tabular}

\section{Conclusion}

The study provides the descriptive statistic result that, the female students attend better than male students but score less than male. This may be due to the fact that female students have more determinant factors for academic performance than male students in lower grades to have basic knowledge which is base for higher institution. Because, the regular attendance is important for the students from the childhood for their better performance (Shaikha Hassan Jameel and Allam Hamdan, 2015). Multiple linear regression output indicates that both gender and attendance have significant influence on academic performance of the student. Gender correlates negatively at $1 \%$ probability level where attendance correlates positively at $1 \%$ probability level with academic performance. Students got good Grade than who missed the classes frequently.

\section{Recommendations}

- The study supports the idea that university should strongly encourage attendance and gender issue for quality education. University should also encourage outstanding female and male students to share their experience for low scorer students.

- Further study should also conduct to examine determinants of the students to perform better on their academics at lower grade and higher institution to strengthen quality education for all.

\section{Abbreviation /Acronyms}

AECD-Adult Education and Community Development

APEX- Animal Production and Extension

ERC- Economic Research Center

RDAE- Rural Development and Agricultural Extension

UNESCO- United Nations Educational, Scientific and Cultural Organization

VIF- Variance of Inflation Factor 


\section{Acknowledgement}

First of all, we are pleased to thank University of Gondar for supporting us to do research activities. It is also our pleasure to thank College of Agriculture and Rural Transformation and our colleagues, Agricultural entrepreneurs in Amhara Region for supporting us for the relevant information, guidance and valuable inputs throughout the study period.

\section{References}

[1] Ahmed Abdi Aden, Zeynab Abdiqadir Yahye, Ahmed Mohamed Dahir, 2013. The effect of student's attendance on academic performance: A Case Study at Simad University Mogadishu .Academic Research International ISSN-L:2223-9553,ISSN:2223-9944 Vol.4 No. 6 november 2013. Faculty of Business and Accountancy, SIMAD University, SOMALIA.

[2] Farooq, M.S., Chaudhry, A.H. Shafiq, M., and Berhanu, G. (2011). Factors affecting students' quality of academic performance: a case of secondary school level. Journal of Quality and Technology Management Volume VII, Issue II, December, 2011. University of the Punjab, Pakistan and University of Gothenburg, Sweden.

[3] Kyoshaba Martha, 2009. Factors Affecting Academic Performance Of Undergraduate Students At Uganda Christian University. Dissertation Submitted To Graduate School In Partial Fufilment Of The Requirements For The Award Of The Degree Of Master Of Arts In Educational Management Of Makerere University.

[4] Meenakshi Narula, Pankaj Nagar, 2013. Relationship Between Students' Performance and Class Attendance in a Programming Language Subject in a Computer Course. International Journal of Computer Science and Mobile Computing. ISSN 2320-088X IJCSMC, Vol. 2, Issue. 8, August 2013, pg.206 - 210. Guru Gobind Singh Indraprastha University, New Delhi, India.

[5] Mohannad Eid AbuRuz, 2015. Does excessive absence from class lead to lower levels of academic achievement? European Scientific Journal March 2015 edition vol.11, No.7 ISSN: 1857 - 7881 (Print) e - ISSN 1857- 7431. Applied Science Private University, Amman, Jordan.

[6] Muhammad Riaz Ahmad, Muhammad Khalid Pervaiz, Muhammad Aleem, 2015. A comparative study of the factors affecting the male and female students' academic performance in higher education (a case of government college university, lahore). European Scientific Journal March 2015 edition vol.11, No.7 ISSN: 1857 - 7881 (Print) e - ISSN 1857- 743.

[7] Nigel Halpern, 2017. Attendance in Higher Education: does it matter? Investigations in university teaching and learning vol. 4 (2) summer 2007 ISSN 1740-5106. Norwegian School of Supply Chain Management \& Logistics Molde University College, Norway.

[8] Peter Ogbianigene Dania,2014. Effect of Gender on Students Academic Achievement in Secondary School Social Studies. Journal of Education and Practice ISSN 2222-1735 (Paper) ISSN 2222-288X 
(Online) Vol.5, No.21, 2014. Department Of Social Science Education, Delta State University, Abraka, Nigeria.

[9] R.Bada.Abubakar and O.Dokubo Oguguo,2011. Age and gender as predictors of academic achievement of college mathematics and science students. Proceedings of the 2011 International Conference on Teaching, Learning and Change (c) International Association for Teaching and Learning (IATEL). Department of Mathematics, Federal College of Education (Technical),Omoku,Rivers State, Nigeria.

[10] Rizwan Faisal, Laiyla Shinwari, Shahzadi Saima Hussain, 2015. Academic performance of male in comparison with female undergraduate medical students in Pharmacology examinations. Vol. 67, No. 2, February 2017 . Rehman Medical College, Govt. P.G.M.I, Lady Reading Hospital, Peshawar.

[11] Sadri ALIJA, 2013. How Attendance Affects the General Success of the Student. International Journal of Academic Research in Business and Social Sciences January 2013, Vol. 3, No. 1 ISSN: 2222-6990. Faculty of Business and Economics, SEEU, Ilindenska bb, Tetovo, Macedonia.

[12] Senate Legislation of university, 2013. Senate Legislation of university December, 2013 Gondar, Ethiopia.

[13] Shaikha Hassan Jameel and Allam Hamdan, 2015. Effects of student's attendance on accounting student's performance. International Journal of Business and Management Review , June 201593 Vol.3, No.5, pp. 79 . Published by European Centre for Research Training and Development UK.

[14] Vincenzo Andrietti_ Rosaria D’Addazio, 2012. Does Class Attendance Affect Academic Performance? Evidence from "D’Annunzio" University Italy. 